\title{
Early prenatal investigation of a pregnancy at risk of adenosine deaminase deficiency using chorionic villi
}

\author{
D A AITKEN*, D H GILMORE $\dagger$, C A FREW*, M E FERGUSON-SMITH*, \\ M J CARTY $\ddagger$, AND W R CHATFIELD $\dagger$ \\ From *the Duncan Guthrie Institute of Medical Genetics, Yorkhill, Glasgow; the Queen Mother's Hospital, \\ Yorkhill, Glasgow; and $\ddagger$ the Southern General Hospital, Glasgow.
}

SUMMARY A pregnancy at risk for adenosine deaminase deficiency and severe combined immunodeficiency disease was investigated using samples of chorionic villi obtained during the eighth week of pregnancy. Adenosine deaminase levels suggested that the fetus was a probable carrier and that a diagnosis of severe combined immunodeficiency disease could be excluded. Enzyme and chromosome results were available within 24 hours of the chorionic villous sampling procedure, and were confirmed on amniotic fluid cell cultures after amniocentesis at 17 weeks' gestation and on cord blood at delivery.

The basic biochemical defect in most forms of severe combined immunodeficiency disease (SCID) is unknown, but a deficiency of the purine catabolic pathway enzyme adenosine deaminase (ADA, E.C.3.5.4.4.) is found in just over $20 \%$ of cases with the autosomally inherited form of the disorder. ${ }^{1}$ Treatment of patients with SCID by enzyme replacement has been attempted ${ }^{2}$ but a successful bone marrow transplant remains the only effective therapy, an option which is available to fewer-than $20 \%$ of patients who have an HLA compatible sib. ${ }^{3}$ Because of the generally poor prognosis, most at risk couples request prenatal diagnosis and selective termination of affected fetuses. Where the ADA deficient form of SCID is identified, prenatal diagnosis can be made by assay of the enzyme in cultured amniotic fluid cells after amniocentesis at 16 to 18 weeks' gestation, ${ }^{45}$ or by analysis of fetal blood samples by enzymology or fetal lymphocyte typing. ${ }^{7}$

We report here the early prenatal investigation of a pregnancy at risk for SCID and ADA deficiency using uncultured cells from chorionic villi obtained at eight weeks' gestation. Within 24 hours of the procedure, a deficiency of ADA in the fetus was excluded and the patient reassured.

\section{Case report}

The patient, a 25 year old $\mathrm{P} 1+1$, gave birth to her

Received for publication 19 November 1984. Accepted for publication 11 January 1985 first child in 1981. The child died aged 1 year with bronchopneumonia and leucopenia. A combined immunodeficiency was suspected and adenosine deaminase (ADA) activity was found to be absent in erythrocytes. Cultured skin fibroblasts and red cells from both parents had intermediate levels of ADA confirming their carrier status. Four months later the patient conceived again and amniocentesis was arranged for 16 weeks' gestation. When the pregnancy was 11 weeks advanced (by dates) the fetus was aborted spontaneously. Fetal cell cultures were found to have normal levels of ADA activity, but a $45, X / 46, X,+7$ chromosome constitution.

Before the couple's third pregnancy the presence of ADA activity had been demonstrated in samples of chorionic villi obtained at early terminations. The parents elected to have the pregnancy monitored by this method with confirmatory amniocentesis at 16 weeks in the event of an unaffected pregnancy being predicted by examination of chorionic villi.

\section{Methods}

Samples of chorionic villi were obtained transcervically during the eighth week of pregnancy under direct vision by suction through an intravenous cannula attached to an endoscope (Olympus arthroscope). Three sampling attempts were made and villi obtained at the second and third attempts were collected in Ham's F10. For ADA assay, three groups of villi (approximately 5 to $10 \mathrm{mg}$, free of blood and adhering maternal decidua) were selected using a dissection microscope. The remaining villi 
were used for fetal sexing ( $Y$ fluorescence) and short term (24 hours) cultures for chromosome analysis. ${ }^{\mathrm{x}}$

For the estimation of ADA activity, the villi were washed in $0.9 \%$ sodium chloride, resuspended in deionised water, and reduced to small fragments by chopping with scissors. The intracellular contents were released by sonication and the resulting suspension cleared by centrifugation at $10000 \mathrm{~g}$ at $4^{\circ} \mathrm{C}$ for 10 minutes. The protein content of the supernatant was estimated by the Lowry method ${ }^{9}$ and adjusted to 0.3 to $0.5 \mathrm{mg} / \mathrm{ml}$ with deionised water.

Amniotic fluid cells were grown in Ham's F10 supplemented with $20 \%$ fetal calf serum and antibiotics. Cells were harvested by trypsinisation, washed in Hank's BSS and $0.9 \%$ sodium choride, and the cell pellet resuspended in deionised water and disrupted by sonication. Protein content of the centrifuged supernatant was adjusted to $0 \cdot 2$ to $0 \cdot 3$ $\mathrm{mg} / \mathrm{ml}$ before assay.

Packed red cells from cord blood collected in heparin were lysed with deionised water and the haemolysate further diluted to a haemoglobin concentration of 0.5 to $1.0 \mathrm{~g} / \mathrm{dl}$.

Lysates of chorionic villi, amniotic fluid cells or red cells were assayed for ADA activity under identical conditions, using a modification of the radioassay method described previously. ${ }^{10}$ A total of $5 \mu \mathrm{l}$ of sample supernatant was mixed with $20 \mu \mathrm{l}$ of $0.25 \mathrm{~mol} / \mathrm{l}$ Tris- $\mathrm{HCl}, \mathrm{pH} 7.4$, containing 0.35 $\mathrm{mmol} / \mathrm{l}{ }^{14} \mathrm{C}$-adenosine. The reaction solution was covered with two drops of oil (paraffin:hexadecane, 80:20) to prevent evaporation and the tubes incubated at $37^{\circ} \mathrm{C}$ for one hour. The reaction was stopped by adding $5 \mu \mathrm{l}$ of cold $20 \%$ trichloroacetic acid and the precipitated proteins removed by high speed centrifugation. The labelled products and unused substrate in $2 \mu \mathrm{l}$ of the clear supernatant were separated by ascending thin layer chromatography on Polyethylimine cellulose-F (PEI-F, Merck) with $5 \% \mathrm{Na}_{2} \mathrm{HPO}_{4}$ as solvent. The inosine and adenosine spots were identified under short wave ultraviolet light, cut out, and the radioactivity quantified by heterogeneous liquid scintillation counting. Results were expressed as nmol adenosine deaminated per hour per mg of homogenate protein (chorionic villi and amniotic fluid cells) or nmol per hour per mg haemoglobin (red cells).

\section{Results}

ADA activity in the chorion biopsy from the pregnancy at risk and in 23 controls is presented in table 1. Control villi were obtained at elective terminations between eight and 12 weeks' gestation. Two of three bloodstained samples had raised levels
TABLE 1 ADA activity in three samples of chorionic villi from the at risk pregnancy and in 23 blood free and three blood stained controls.

\begin{tabular}{lll}
\hline & & $\begin{array}{l}\text { ADA activity } \\
\text { (nmol/h/mg protein) }\end{array}$ \\
\hline At risk pregnancy & Sample (a) & $222 \cdot 6$ \\
& (b) & $212 \cdot 0$ \\
Controls $(\mathrm{n}=20)$ & (c) & $208 \cdot 1$ \\
& Sean & 429 \\
Blood stained villi $(\mathrm{n}=3)$ & Range & 157 \\
& Mean & $220-701$ \\
& SD & 739 \\
& Range & 141 \\
& & $580-848$ \\
\hline
\end{tabular}

of ADA activity reflecting contamination by the higher specific activity red cell enzyme. No difference in activity was found for samples assayed immediately after collection and after storage at $-20^{\circ} \mathrm{C}$ for several weeks. ADA activity in chorionic villi from the pregnancy at risk was $50 \%$ of the mean of the control group, suggesting heterozygosity in the fetus.

Chromosome analysis after a 24 hour culture of cells from the chorion biopsy showed a normal male karyotype. The presence of a Y chromosome was confirmed by fluorescence analysis of interphase nuclei.

The results obtained in the chorionic villi were confirmed in AF cell cultures after amniocentesis at 17 weeks' gestation and in cord blood at delivery (table 2). Definite carrier status could not be ascribed to the infant from ADA activities determined in cultured AF cells or cord blood, since both tissues had activities which were just within the lower limits of the respective normal ranges.

Phytohaemagglutinin stimulated cultures of lymphocytes from cord blood showed the presence of a large number of mitotic cells indicating normal lymphocyte proliferation, thus supporting the prenatal diagnosis of a pregnancy unaffected by severe combined immunodeficiency and adenosine deaminase deficiency.

TABLE 2 ADA activity in cultured amniotic fluid cells from the at risk pregnancy and in cord blood.

$A D A$ activity*

\begin{tabular}{lll}
\hline AF cell cultures & & \\
At risk pregnancy & & 276 \\
Controls $(n=9)$ & Mean & 446 \\
& SD & 132 \\
& Range & $236-702$ \\
Erythrocytes & & \\
Baby M (cord blood) & & $36 \cdot 7$ \\
Controls (venous blood) & Mean & $62 \cdot 2$ \\
$\quad(n=22)$ & SD & $12 \cdot 6$ \\
& Range & $36 \cdot 5-86 \cdot 2$ \\
\hline
\end{tabular}

${ }^{*} \mathrm{Nmol} / \mathrm{h} / \mathrm{mg}$ protein for AF cells. nmol/h/mg hacmoglobin for red cells. 


\section{Discussion}

The established method of prenatal diagnosis of chromosome abnormalities and most metabolic diseases depends upon culture of fetal cells obtained by amniocentesis after the 15 th week of pregnancy. Considerable anxiety is experienced by parents during the period required for cell culture before results can be obtained (up to four weeks) and where a positive diagnosis is made there is the additional distress of a mid-trimester termination. Microscale methods of analysis which require only small numbers of cultured cells, and thus a correspondingly reduced cultivation period, have been applied to the prenatal diagnosis of a variety of metabolic diseases ${ }^{11}$ including ADA deficiency, ${ }^{10}$ and this approach can substantially reduce the period between amniocentesis and diagnosis. Alternatively, where the metabolic error is expressed in fetal blood, as is the case with ADA deficiency and SCID, sufficient material for direct analysis can be obtained by fetoscopy and fetal blood sampling. ${ }^{6}$ However, these approaches, although providing a more rapid diagnosis, cannot be undertaken until 16 to 20 weeks' gestation owing to the need to obtain fetal tissue by amniocentesis or fetoscopy.

In the present communication we report the prenatal exclusion of ADA deficiency and SCID by the eighth week of pregnancy. Direct analysis on samples of chorionic villi eliminates the delay and uncertainty associated with long term cell culture and enzyme results were available within 24 hours of the sampling procedure, providing early reassurance for the patient. There was good agreement in ADA activity, measured as a percentage of the mean of the appropriate control group, between chorionic villi, cultured amniotic fluid cells, and cord blood. Thus, it is likely that the status of the fetus with respect to ADA activity is accurately reflected in samples of uncultured chorionic villi and that a deficiency of ADA activity could be readily identified, as has already been demonstrated for other inborn errors of metabolism. ${ }^{12}$ Where intervention is indicated, termination of a pregnancy at eight to ten weeks is a safer, simpler, and much less traumatic experience for the patient than the corresponding procedure at 20 weeks' gestation.

As yet the risk to a continuing pregnancy after chorionic villi sampling cannot be accurately defined because of the limited experience obtained with a small number of diagnostic cases and the added complication of a high rate of spontaneous abortion in early pregnancy. However, provided the true risk is low and fetal tissue samples of adequate size uncontaminated with blood or maternal decidua can be obtained, then chorionic villi sampling is likely to become the method of choice for the prenatal diagnosis of a variety of metabolic diseases.

The support of the National Fund for Research into Crippling Diseases and the ADAGENE fund is gratefully acknowledged.

\section{References}

1 Hirschhorn R. Incidence and prenatal detection of adenosine deaminase deficiency and purine nucleoside phosphorylase deficiency. In: Pollara B, Pickering RJ, Meuwissen HJ, Porter IH, eds. Inborn errors of specific immunity. New York: Academic Press, 1979:5-12.

2 Polmar SH. Red cell therapy: its clinical and immunological efficacy in ADA deficiency. In: Pollara B, Pickering RJ, Meuwissen HJ. Porter $\mathrm{IH}$, eds. Inborn errors of specific immunity. New York: Academic Press, 1979:343-8.

3 Linch DC, Levinsky RJ. Prenatal diagnosis of immunodeficiency disorders. Br Med Bull 1983;39:399-404.

${ }^{4}$ Hirschhorn R, Beratis N, Rosen FS, Parkman R, Stern R, Polmar S. Adenosine deaminase deficiency in a child diagnosed prenatally. Lancet 1975;i:73-5.

5 Ziegler JB, van der Weyden MB, Lee CH, Daniel A. Prenatal diagnosis for adenosine deaminase deficiency. $J$ Med Genet 1981;18:154-6.

6 Simmonds HA, Fairbanks LD, Webster DR, Rodeck $\mathrm{CH}$, Linch DC, Levinsky RJ. Rapid prenatal diagnosis of adenosine deaminase deficiency and other purine disorders using fetal blood. Bioscience Rep 1983;3:31-8.

7 Linch DC, Levinsky RJ, Rodeck CH, MacLennan KA Simmonds HA. Prenatal diagnosis of three cases of severe combined immunodeficiency: severe $T$ cell deficiency during the first half of gestation in fetuses with adenosine deaminase deficiency. Clin Exp Immunol 1984;56:223-32.

${ }^{8}$ Gregson NM, Seabright M. Handling chorionic villi for direct chromosome studies. Lancet 1983;ii: 1491.

9 Lowry OH, Rosebrough NJ, Farr AL, Randall RJ. Protein measurement with the Folin phenol reagent. J Biol Chem 1951:193:265-75.

10 Aitken DA, Kleijer WJ, Niermeijer MF, Herbschleb-Voogte E, Galjaard H. Prenatal detection of a probable heterozygote for ADA deficiency and severe combined immunodeficiency disease using a microradioassay. Clin Genet 1980;17:293-8.

1 Galjaard H. Genetic metabolic diseases. Early diagnosis and prenatal analysis. Amsterdam: Elsevier/North Holland, 1980. O

12 Kleijer WJ, van Diggelen OP, Janse HC, Galjaard H, Dumez N Y, Boue J. First trimester diagnosis of Hunter syndrome on chorionic villi. Lancet $1984 ;$;i: 472 .

Correspondence and requests for reprints to Dr D A Aitken, Duncan Guthrie Institute of Medical Genetics, Yorkhill, Glasgow G3 8SJ.

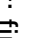

